\title{
The Mean Age of Ocean Waters Inferred from Radiocarbon Observations: Sensitivity to Surface Sources and Accounting for Mixing Histories
}

\section{Citation}

Gebbie, Geoffrey, and Peter John Huybers. 2012. The mean age of ocean waters inferred from radiocarbon observations: Sensitivity to surface sources and accounting for mixing histories. Journal of Physical Oceanography 42(2): 291-305.

\section{Published Version}

doi:10.1175/JPO-D-11-043.1

\section{Permanent link}

http://nrs.harvard.edu/urn-3:HUL.InstRepos:8965539

\section{Terms of Use}

This article was downloaded from Harvard University's DASH repository, and is made available under the terms and conditions applicable to Other Posted Material, as set forth at http:// nrs.harvard.edu/urn-3:HUL.InstRepos:dash.current.terms-of-use\#LAA

\section{Share Your Story}

The Harvard community has made this article openly available.

Please share how this access benefits you. Submit a story.

\section{Accessibility}




\title{
The Mean Age of Ocean Waters Inferred from Radiocarbon Observations: Sensitivity to Surface Sources and Accounting for Mixing Histories
}

\author{
GEOFFREY GEBBIE \\ Department of Physical Oceanography, Woods Hole Oceanographic Institution, Woods Hole, Massachusetts \\ PETER HuYBERS \\ Harvard University, Cambridge, Massachusetts
}

(Manuscript received 18 February 2011, in final form 30 September 2011)

\begin{abstract}
A number of previous observational studies have found that the waters of the deep Pacific Ocean have an age, or elapsed time since contact with the surface, of 700-1000 yr. Numerical models suggest ages twice as old. Here, the authors present an inverse framework to determine the mean age and its upper and lower bounds given Global Ocean Data Analysis Project (GLODAP) radiocarbon observations, and they show that the potential range of ages increases with the number of constituents or sources that are included in the analysis. The inversion requires decomposing the World Ocean into source waters, which is obtained here using the total matrix intercomparison (TMI) method at up to $2^{\circ} \times 2^{\circ}$ horizontal resolution with 11113 surface sources. The authors find that the North Pacific at 2500-m depth can be no younger than $1100 \mathrm{yr}$ old, which is older than some previous observational estimates. Accounting for the broadness of surface regions where waters originate leads to a reservoir-age correction of almost $100 \mathrm{yr}$ smaller than would be estimated with a two or three water-mass decomposition and explains some of the discrepancy with previous observational studies. A best estimate of mean age is also presented using the mixing history along circulation pathways. Subject to the caveats that inference of the mixing history would benefit from further observations and that radiocarbon cannot rule out the presence of extremely old waters from exotic sources, the deep North Pacific waters are 1200-1500 yr old, which is more in line with existing numerical model results.
\end{abstract}

\section{Introduction}

A useful but simple bulk indicator of the circulation is the time since water was last at the surface, which is commonly known as the "age" of seawater. Radiocarbon observations are helpful for determining age, because radiocarbon is not produced in the ocean, the radioactive decay rate is known, and its half-life is in the right range. The age of the deep Pacific has been estimated from radiocarbon observations to be generally less than $1000 \mathrm{yr}$ (Stuiver et al. 1983; Metz et al. 2005; Matsumoto 2007) and is sometimes described as a centennial rather than millennial time scale. General circulation models (GCMs) have also been used to estimate ocean age, but, although the concentration of radiocarbon produced by the models is consistent with the observational studies, the

Corresponding author address: Geoffrey Gebbie, Woods Hole Oceanographic Institution, MS \#29, Woods Hole, MA 02543.

E-mail: ggebbie@whoi.edu inferred ages are not. Modeling studies report a maximum age for the deep North Pacific between 1500 and 2000 yr (England 1995; Deleersnijder et al. 2001; Primeau 2005; Peacock and Maltrud 2006), such that the discrepancy in age estimates from different methods approaches $100 \%$.

Is the ocean age discrepancy due to model errors, data errors, or some error in interpretation? The error in the Global Ocean Data Analysis Project (GLODAP) gridded radiocarbon values is no larger than $30 \%$ (Key et al. 2004), enough to make a difference of $400 \mathrm{yr}$ for the age of the deep Pacific, but this is unlikely to represent a systematic error in the entire basin and it is still too small to explain the entire model-data discrepancy. The accuracy of the model results can always be questioned (e.g., due to inadequate resolution), but the fact that the modeled radiocarbon concentrations are consistent with the observations instead suggests some issue in the interpretation of age.

Any subsurface location may be accessed by multiple pathways that trace back to the surface. These pathways 
are a combination of advective and diffusive effects and generally have a wide distribution of transit times from the surface to any particular interior point (Holzer and Hall 2000; Deleersnijder et al. 2001; Waugh et al. 2003). The focus of this work is the mass-weighted average age of ocean waters, or the "mean age," which is here defined to be the mean of the pathway transit times from the mixed layer to the interior. The total amount of remineralized nutrient (or utilized oxygen) along a pathway is related to mean age, making this quantity particularly relevant. Because of the spectrum of transit times, any one scalar cannot convey all transport information, but the mean age represents the centered first moment of the distribution, a natural quantity on which to focus. Previous measures of the time scale of circulation, such as replacement times (Stuiver et al. 1983; Primeau and Holzer 2006; Broecker et al. 2007) or equilibration times (Wunsch and Heimbach 2008), may be rather different than the mean age of the ocean and their relationship is usually not trivial.

Accurate inference of age from radiocarbon requires accounting for the pathways that link the interior and surface for two distinct reasons. First, although the atmosphere is relatively well mixed in radiocarbon activity, the surface ocean can maintain a significant and spatially variable disequilibrium (e.g., Broecker and Peng 1982; Broecker et al. 1991). Indeed, the range of surface radiocarbon concentrations is about $70 \%$, whereas the deep ocean range is $200 \%$, making the range of surface concentrations a significant proportion of the total. Second, the exponential decay of radiocarbon gives young waters a disproportionate influence on radiocarbon concentration, and this tends to bias age estimates toward younger values (e.g., Deleersnijder et al. 2001). This bias (here called the radiocarbon-age bias) arises because radiocarbon age is not conserved under mixing processes as it is a nonlinear function of radiocarbon concentration (e.g., Wunsch 2002). We hypothesize that an incomplete accounting of the multitude of ocean pathways is responsible for errors in the interpretation of the radiocarbon observations, leading to the discrepancy between modeled and observationbased estimates of ocean age.

Our approach involves first applying the recently developed TMI method to a suite of modern-day observations, including temperature, salinity, $\delta^{18} \mathrm{O}$ of seawater, phosphate, nitrate, and dissolved oxygen (e.g., Gouretski and Koltermann 2004; Legrande and Schmidt 2006). The data are at $2^{\circ} \times 2^{\circ}$ horizontal resolution, giving a total of 11113 surface origination sites (Gebbie and Huybers 2010). The use of six tracers along with the accounting for their inherent geographical relationships by TMI has been shown to be sufficient to provide a unique and well-constrained solution to the water-mass decomposition problem in three dimensions. Here, we extend the TMI method to also incorporate radiocarbon observations (section 2). We then discuss the observations and inputs for the global problem (section 3 ) and show that estimates of mean age depend upon the number of constituents included in the analysis, explaining the aforementioned differences between observational and modeling estimates of age (section 4). We also provide a best estimate of the mean age that specifically accounts for the mixing histories of waters (section 5) and then discuss these results relative to previous estimates in the conclusions (section 6).

\section{Formulation of radiocarbon inverse model}

We begin with a general formulation for calculating age from radiocarbon observations. Radiocarbon concentration at an interior ocean point $C$ is due to contributions from multiple constituents (e.g., Holzer and Hall 2000; Khatiwala et al. 2001; Haine and Hall 2002), with the individual contributions decaying according to an age distribution $G_{i}(t)$,

$$
C=\sum_{i=1}^{N} m_{i} C_{i} \int_{0}^{\infty} G_{i}(t) e^{-\lambda t} d t
$$

where $N$ is the number of constituents, $m_{i}$ is the mass fraction of the $i$ th constituent, $C_{i}$ is the initial radiocarbon concentration for that constituent, and $\lambda$ is set by the radioactive decay rate $[\lambda=\log (2) / 5730 \mathrm{yr}]$. Each constituent refers to waters with a particular initial radiocarbon value, whether it is a water mass, a water type, or waters identified by their surface origin. The mass fractions are bounded by 0 and 1 , and their sum must equal one for mass conservation. All age distributions must satisfy $\int_{0}^{\infty} G_{i}(t) d t=1$, which makes our $G_{i}(t)$ functions similar to the boundary propagator Green function of Haine and Hall (2002) but with a different normalization. The function $G_{i}(t)$ is also the distribution of transit times from the source region of constituent $i$ to the particular interior location, though note that the related term "transit time distribution" (TTD) is usually reserved for the case where the source region is the global sea surface. We seek the mean age,

$$
\bar{T}=\sum_{i=1}^{N} m_{i} \int_{0}^{\infty} t G_{i}(t) d t,
$$

and note that the age of each constituent can also be individually defined as $\bar{T}_{i}=\int_{0}^{\infty} t G_{i}(t) d t$. Radiocarbon values are expressed as a ratio with carbon-12 and we 
have not explicitly represented the latter, given its large and constant distribution relative to radiocarbon, though Fiadeiro (1982) calculated that this may lead to as much as $10 \%$ error and this assumption should be revisited in future work.

Inference of mean age depends upon three uncertain quantities: the observations of radiocarbon concentration, affecting both $C$ and $C_{i}$ in Eq. (1); the water-mass decomposition given by the $m$ values; and the age distribution of the constituents $G_{i}(t)$. The uncertainty in radiocarbon arises from observational errors, the need to map those observations onto a regular grid, and the separation of radiocarbon into background and bomb components, which will be discussed in section 3. Holzer et al. (2010) discuss the sensitivity of age to uncertainties in water-mass decomposition, albeit using a different technique, which we also address in section 4. Even in the case that the water-mass decomposition and source radiocarbon values are well known, a radiocarbon observation provides only one constraint on $N$ unknown $G_{i}(t)$ functions, making for a highly underdetermined problem. The net effect of advection and diffusion determines the form of $G_{i}(t)$, and below we develop an inverse framework to explore the importance of these transport characteristics by finding upper and lower bounds on mean age under the assumption of known $m_{i}$ and $C_{i}$ values.

\section{a. Lower bound}

To find the youngest mean age possible with a given radiocarbon observation, we minimize the left-hand side of Eq. (2) subject to the constraint of Eq. (1), solved using an extended Lagrange multipliers method (see the appendix for the detailed derivation). If radiocarbon source values and contributions are known, the lower bound on mean age occurs when $G_{i}(t)=\delta\left(t-T_{i}\right)$, where $\delta$ is the Dirac delta function and

$$
T_{i}=\frac{1}{\lambda} \log \left(\frac{C_{i}}{C}\right)
$$

indicating purely advective transport of the $i$ th constituent with an age $T_{i}$. Back substituting into Eq. (2) we obtain the lower bound on mean age,

$$
\bar{T}_{\min }=\sum_{i=1}^{N} \frac{m_{i}}{\lambda} \log \left(\frac{C_{i}}{C}\right) .
$$

This solution is only feasible, however, if $C_{i} \geq C$; otherwise, some transit times would be unphysically negative. This data constraint does not always hold, but Eq. (4) can be extended for the more general case (see also the appendix).
The lower bound on mean age is similar to the age that is often inferred from radiocarbon (e.g., Broecker et al. 1991), which is referred to here as the "standard" radiocarbon age, $T_{\lambda}=(1 / \lambda) \log \left(C_{o} / C\right)$, where $C_{o}$ is the amount of radiocarbon that would be present without any radioactive decay (i.e., the preformed radiocarbon content, $\left.C_{o}=\sum_{i=1}^{N} m_{i} C_{i}\right)$. The standard radiocarbon age scenario corresponds to a solution of Eqs. (1) and (2) with $G_{i}(t)=\delta\left(t-T_{\lambda}\right)$ for all $i$, corresponding to purely advective transport with an identical age for all constituents, a situation that is unlikely to be realistic. In the lower bound case, the $G_{i}(t)$ functions also correspond to a purely advective transport, but the age of the different constituents need not be equal. Thus, the implied $G_{i}(t)$ functions in the standard radiocarbon age calculation are different from the lower bound solution so long as the surface radiocarbon content is not uniform, showing that the standard radiocarbon age is generally older than the lower bound, contrary to previous derivations (e.g., Deleersnijder et al. 2001).

For reference later in this work, we rewrite the radiocarbon-age formula in the customary way, $T_{\lambda}=$ $-(1 / \lambda) \log (C)-T_{\text {res }}$, where the apparent radiocarbon age due to the deficit from atmospheric radiocarbon levels is corrected by the reservoir age, $T_{\text {res }}=-(1 / \lambda)$ $\log \left(C_{o}\right)$, because of surface disequilibrium effects (e.g., Broecker et al. 1991). Thus, the reservoir age is defined at the surface based upon the surface radiocarbon values, and a reservoir-age correction can be diagnosed for all interior locations so long as the constituents of that location can be tracked back to the surface.

\section{b. Upper bound}

There are two scenarios where oceanic transport characteristics lead to a mean age that is much older than the lower bound calculated above, even when the observed radiocarbon concentration is unchanged. One scenario occurs when the individual $G_{i}(t)$ functions are very wide due to diffusive transport, and the long tail of $G_{i}(t)$ gives a large mean age when integrating Eq. (2) across the full range of times from zero to infinity. As is well known, the form of $G_{i}(t)$ is weakly constrained for large $t$ because old waters no longer contain much radiocarbon due to decay. Another lesser-discussed scenario occurs when there is a wide range in the relative age of the individual constituents. We give an example of this effect next, where the mean age is much larger than the lower bound, even though the individual constituents have delta functions for $G_{i}(t)$, and show the dependence on the number of constituents considered in the analysis.

Consider a simple case where an interior location is composed of $N$ constituents with the same initial 


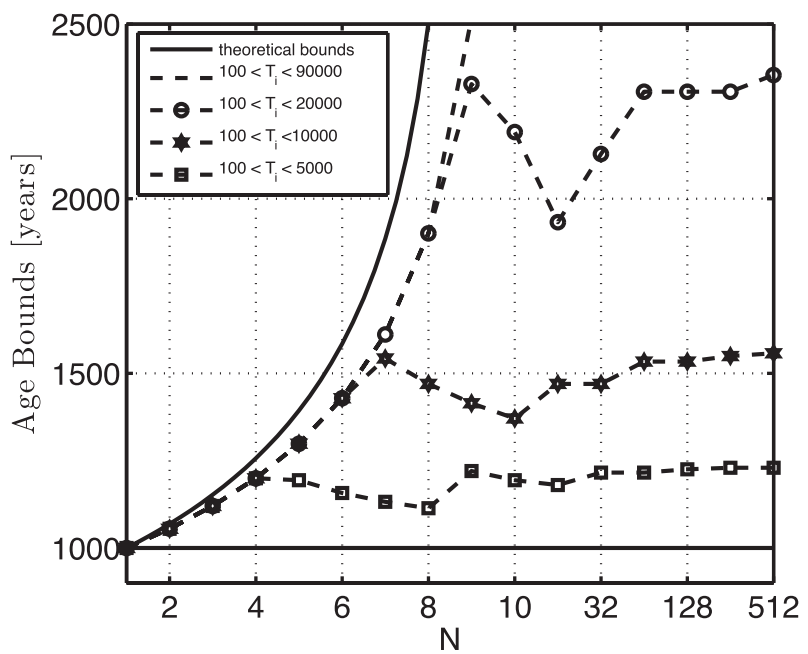

FIG. 1. Bounds on the mean age of a hypothetical water parcel with a fixed radiocarbon concentration as a function of the number of equal-sized constituents $N$. The theoretical upper bound (solid curved line) increases with $N$, whereas the lower bound is unchanging at $1000 \mathrm{yr}$ and is equivalent to the standard radiocarbon age. The upper bound decreases as the maximum age of each constituent is lowered (see legend). Note the change in scale along the $x$ axis and that the variability in the bounds comes from the restriction to integer numbers of constituents. Beyond $N=512$, the age bounds are nearly unchanging.

radiocarbon concentration, $C_{i}=C_{o}$, and equal mass contributions, $m_{i}=1 / N$. The interior radiocarbon content is set such that the standard radiocarbon age is exactly $1000 \mathrm{yr}\left(C / C_{o}=0.88\right)$. From Eq. (4), the lower bound is the same for any number of constituents $N$, and it is identical to the standard radiocarbon age (flat solid line in Fig. 1). The theoretically oldest mean age is obtained when $N-1$ constituents have zero age and the $N$ th constituent is maximally old, as follows from the radiocarbon constraint being weakest upon the oldest contributions and can be shown rigorously using linear programming methods. Therefore, under the simplifications that we have imposed on this problem, $G_{N}(t)=$ $\delta\left(t-T_{N}\right)$ and Eq. (1) reduces to

$$
\frac{C}{C_{o}}=\frac{N-1}{N}+\frac{e^{-\lambda T_{N}}}{N} .
$$

Solving for $T_{N}$, and noting that the mean age is $T_{N} / N$, gives an upper bound on mean age,

$$
\bar{T}_{\max }=-\frac{1}{N \lambda} \log \left[N\left(\frac{C}{C_{o}}-1\right)+1\right],
$$

which holds while $N$ is small enough that the argument of the logarithm is positive. The upper bound increases rapidly as $N$ increases (solid curved line in Fig. 1), and, when $N$ is greater than $1 /\left(C_{o}-C\right)$, the $N$ th constituent need not deliver any radiocarbon to the observational site, allowing $T_{N}$ and $\bar{T}_{\text {max }}$ to be formally infinite.

There are cases where very small or large ages for the individual constituents will not be realistic, but the general tendency for the upper bound to increase with $N$ will nonetheless hold even if the range of admissible ages is limited. For instance, limiting the mean age of each constituent to be between 100 and $10000 \mathrm{yr}$ gives an upper bound of more than $1500 \mathrm{yr}$ as $N$ increases, and thus the range of possible mean ages is $50 \%$ of the radiocarbon age (Fig. 1). Furthermore, an upper bound of $10000 \mathrm{yr}$ for any one contribution is somewhat conservative, given that extremely old waters can be derived from meltwater fluxed directly from the cryosphere to the ocean (e.g., Straneo et al. 2011), groundwater seepage, and waters derived from the earth's interior (e.g., Kadko et al. 1995).

This exercise of exploring upper and lower age bounds given uncertainty in the constituent age distributions thus provides three indications of why observational age estimates tend to be younger than those inferred by general circulation models. First, the standard radiocarbon age computed from observations is expected to be similar to the youngest possible age, up to differences in initial radiocarbon values. Second, many of the previous observational estimates considered just a few water-mass constituents, which excludes many of the scenarios that have much older ages, as seen in the sensitivity of the upper bound with number of constituents. Finally, although we have focused on purely advective solutions, the inclusion of the broadening effects of diffusion upon the age distributions will also tend to increase the age of waters for a given radiocarbon observation in a manner similar to increasing the number of constituents. It should also be noted that placing bounds on the age is complementary to standard error or quartile error (e.g., Holzer and Primeau 2010), especially in the case of distributions that can have long tails. We now turn toward applying these insights to the actual data.

\section{Decompositions and data}

\section{a. Total matrix intercomparison decompositions}

Given the apparent dependence of the range of admissible ages upon the number of constituents, we seek a range of solutions at different resolutions. The highest resolution solutions come from the total matrix intercomparison (TMI) method and are available at $4^{\circ} \times 4^{\circ}$ and $2^{\circ} \times 2^{\circ}$ gridding for a total of 2806 and 11113 different constituents, respectively (Gebbie and Huybers 2010, 2011). This solution method can be viewed as an 
extension of water-mass decompositions to having many more waters, all defined by the particular surface region of origin. The chief insight that TMI calls upon is that six pieces of tracer information at each location $\left(\theta, S, \delta^{18} \mathrm{O}_{\mathrm{sw}}\right.$, $\mathrm{PO}_{4}, \mathrm{NO}_{3}$, and $\mathrm{O}_{2}$ ) are sufficient to provide a unique solution to the ocean pathways interconnecting every grid box because there are, at most, six neighbors to any grid box.

The uncertainties inherent to the TMI solution have been explored in several ways. A twin data assimilation experiment with a general circulation model and an experiment with artificial noise added to the observations both indicated that the TMI reconstructions had less than 5\% error (Gebbie and Huybers 2010). Other potential sources of error may be due to the steady-state structure of the model, but over 2 million tracer observations can be explained as being in equilibrium with the flow field, lending confidence that the model formulation is adequate for our purposes and that uncertainties in the contributions from different constituents are a minor source of error in the present study. The TMI results were also shown to be consistent with $\delta^{13} \mathrm{C}$ observations from the Geochemical Ocean Section Study (GEOSECS; Kroopnick 1985), even though these observations were not used to develop the pathways model (Gebbie and Huybers 2011). Similarly, radiocarbon observations have not been used to constrain the ocean decomposition, as done elsewhere (e.g., Holzer et al. 2010), though later we show that these data too are consistent with the present solution, supporting its accuracy and demonstrating that radiocarbon does not provide a major new water-mass constraint over the tracers already used.

The TMI results also provide a self-consistent way to decompose the ocean into a smaller number of constituents. We divide the ocean surface into seven major regions (see Fig. 2), where all waters originating from a region are grouped together as a common constituent. The tracer source value or "effective end member" for each region is defined as the weighted average of the surface tracer values where the weights are set according to the volume contribution of each surface location to the interior (Gebbie and Huybers 2011). We then apply a standard water-mass decomposition to these endmember values (Mackas et al. 1987; Tomczak and Large 1989), not including the geographic constraints contained in TMI, to simultaneously satisfy the six tracer conservation equations and conservation of mass while also using stoichiometric ratios to model nonconservative effects in nutrients and oxygen (Anderson and Sarmiento 1994; Karstensen and Tomczak 1998). In particular, an independent nonnegative least squares problem is solved at every interior location (Lawson and Hanson 1974).

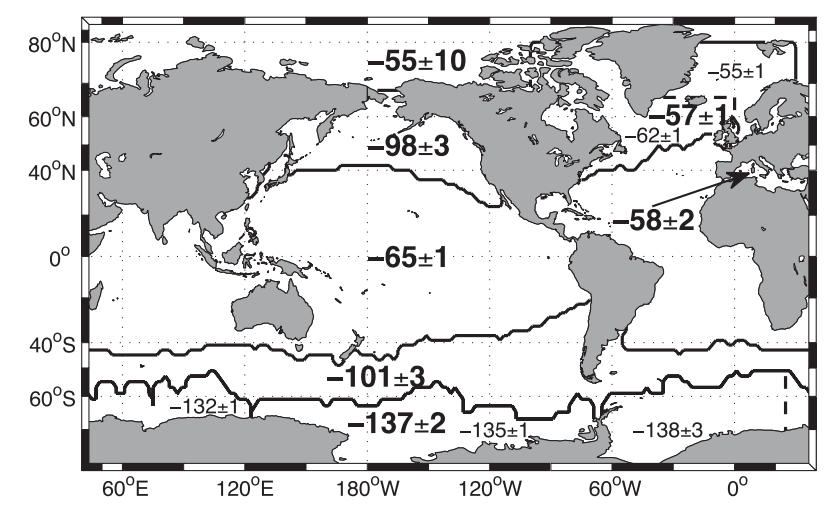

FIG. 2. Effective end members for $\Delta^{14} \mathrm{C}$. Bold values indicate the end-member values for the seven major surface regions delineated by bold lines. Numerical values in smaller font are given for subregions marked by dashed lines. All boundaries are chosen by locations of oceanographic or geographic relevance following Gebbie and Huybers (2010).

The low-resolution TMI solution of the previous paragraph uses all seven major surface regions, but we also obtain solutions with just the Antarctic (ANT), North Atlantic (NATL), and Subantarctic (SUBANT) regions and with just the Antarctic and North Atlantic regions. Thus, we have ocean decompositions at five different resolutions, with $N$ equaling 2, 3, 7, 2806, and 11 113. Additional errors are present in the decompositions with a small number of constituents because they underestimate the variety of different waters that fill the ocean's interior and ignore the geographic constraints of the more complete solution, but we depend upon these less for accuracy than as a means of illustrating how the solution will depend upon $N$.

\section{b. Radiocarbon observations}

The GLODAP gridded dataset of preanthropogenic (or, equivalently, natural or background) radiocarbon is reported in terms of $\Delta^{14} \mathrm{C}$ by measuring the total modern-day radiocarbon from a number of hydrographic sections and subtracting the bomb-produced component (Key et al. 2004). The bomb component has been determined from the strong linear correlation between natural radiocarbon and potential alkalinity (Rubin and Key 2002), a step that introduces uncertainties that we take into account using the published error estimates, but we do not attempt to recalculate the bomb component. Note that $\Delta{ }^{14} \mathrm{C}$ values have also been corrected for fractionation effects using $\delta^{13} \mathrm{C}$. The standard measurement error in radiocarbon has been reported to be $5 \%$, but in the gridded dataset the published errors are $20 \%$ or larger in some regions because of the scarcity of measurements and the type of gridding scheme employed. 
The dataset is box averaged onto a resolution of $2^{\circ} \times 2^{\circ}$ in the horizontal with 33 vertical levels, but it does not cover the full globe because of limitations in regions such as the Arctic Ocean. Here, we confine our internal estimates to locations where GLODAP data are available and extrapolate surface data where necessary. Missing points in the Arctic (ARC), for example, have been assumed to be $-55 \%$ based on a few transects (Jones et al. 1994; Schlosser et al. 1997), and we later check our results with different values for the Arctic. For all calculations, $\Delta^{14} \mathrm{C}$ is transferred into terms of $C \equiv \Delta^{14} \mathrm{C} / \Delta{ }^{14} \mathrm{C}_{\mathrm{atm}}$, so that a $\Delta^{14} \mathrm{C}$ value of $0 \%$ is equivalent to $C=1$.

\section{Age and resolution of ocean constituents}

In this section, we test the hypothesis that differences between age estimates in the deep North Pacific can be traced back to the number of constituents $N$ used in the analysis. Specifically, we focus on the average properties of a box containing some of the oldest ocean waters [called the Northeast Pacific (NEPAC) box: $20^{\circ}-50^{\circ} \mathrm{N}$, $160^{\circ}-110^{\circ} \mathrm{W}$, and $2000-4000-\mathrm{m}$ depth]. We proceed by solving the inverse problem of section 2 according to the appendix, with the same data used by previous investigators and the only difference being the addition of a more complete set of $N$ sources. This analysis aims to be more than pedagogical as other studies have used very small $N$ values (i.e., $N \leq 7$ ), and we wish to provide a context to compare these against the higher-resolution results presented here. As shown in section 2, the upper bound depends strongly upon the a priori limitations imposed on the age of individual constituents, and here we take 100 and $20000 \mathrm{yr}$ as the limits on any constituent, under the reasoning that we do not want to rule out any possibilities without good cause. The results of this section show that the lower values of previous age estimates are partially due to the small number of water masses used.

\section{a. Range of solutions as a function of $N$}

The range of possible ages that satisfy the observed radiocarbon content of the NEPAC box increases from 68 yr at $N=2$ to many thousands of years at $N=11113$, almost exclusively because of an increase in the upper bound (Fig. 3). In the $N=2$ case, the solution is represented by just two time scales, $T_{\mathrm{ANT}}$ and $T_{\mathrm{NATL}}$, the mean age of Antarctic and North Atlantic waters, respectively. Using inputs for the NEPAC box from Fig. 2 and Table $1\left(C_{\mathrm{ANT}}=0.863, C_{\mathrm{NATL}}=0.943, m_{\mathrm{ANT}}=\right.$ 0.69 , and $m_{\mathrm{NATL}}=0.31$ ) and plugging into Eq. (3), the minimum mean age is $1191 \mathrm{yr}$ with $T_{\mathrm{ANT}}=963 \mathrm{yr}$ and $T_{\mathrm{NATL}}=1691 \mathrm{yr}$ (triangle in Fig. 4). Although neither $T_{\mathrm{ANT}}$ nor $T_{\mathrm{NATL}}$ is well constrained individually, the mean age appears bounded to a range of $68 \mathrm{yr}$ when only

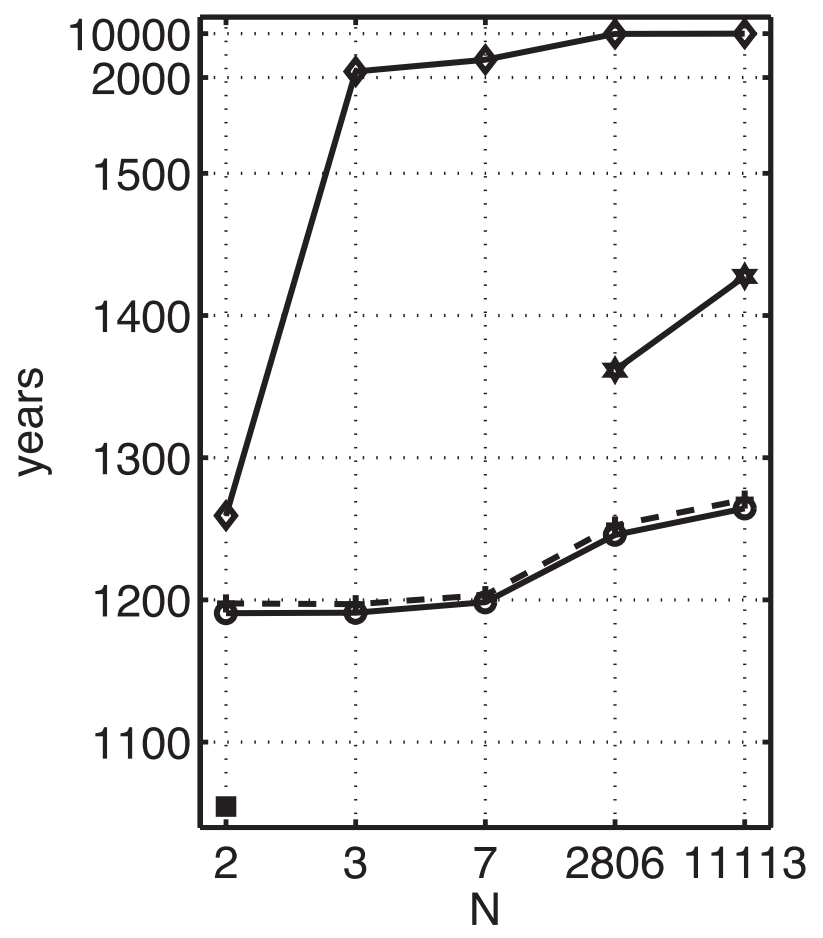

FIG. 3. Inferred mean age and bounds of the deep NEPAC box as a function of the number of constituents $N$. Shown are the upper bound (diamonds), the best estimate of mean age (stars; discussed in section 5), the standard radiocarbon age (plus signs connected by dashed line), the lower limit (circles), and an age estimate using the method of Matsumoto (2007) (square). Note that the age scale becomes logarithmic above $1500 \mathrm{yr}$.

two end members are present. The apparent strong constraint is geometrically seen to be due to the background contours of mean age roughly following the curve of the radiocarbon constraint in the figure.

With $N=2$, the range of possible solutions to the radiocarbon equation was limited to a line in $\left\{T_{1}, T_{2}\right\}$ space, but, for $N=3$, there are many more feasible solutions, constituting a surface in $\left\{T_{1}, T_{2}, T_{3}\right\}$ space. Given a best estimate of the North Pacific decomposition where Subantarctic source waters are now included $\left(m_{\mathrm{ANT}}=0.62, m_{\mathrm{NATL}}=0.26\right.$, and $\left.m_{\mathrm{SUBANT}}=0.12\right)$, the solution space can be represented as a two-dimensional slice where $T_{\text {SUBANT }}$ is not shown but has a value that satisfies the radiocarbon constraint (Fig. 5). The lower limit on mean age for $N=3$ is unchanged at $1191 \mathrm{yr}$, with an implied Subantarctic transit time of $1299 \mathrm{yr}$ (triangle in Fig. 5), but the upper limit for mean age given $N=3$ is $2235 \mathrm{yr}$ (inverted triangle in Fig. 5), much larger than for $N=2$.

The uncertainty found in the mean age is greatly increased going from two to three constituents and a similar pattern is found as the number of constituents increases. As the model of the ocean decomposition 




FIG. 4. Possible ages of the deep NEPAC box given only two constituents. All solutions that satisfy the observed radiocarbon concentration are represented by the bold line, where mean age is indicated by the contours. The lower limit of mean age is $1191 \mathrm{yr}$ (triangle) and the upper limit is $1259 \mathrm{yr}$, assuming that $T_{\mathrm{ANT}} \geq 300, T_{\mathrm{NATL}} \geq 300$ (inverted triangle). If the two transit times are equal (dashed line), only one solution exists (intersection of dashed and bold lines), which is the standard radiocarbon age of $1198 \mathrm{yr}$, illustrating that the lower bound can be less than the standard radiocarbon age, although the difference is only $7 \mathrm{yr}$.

becomes more complete, it reveals a potential for older ages that is otherwise hidden by oversimplified diagnostic frameworks.

\section{b. Reservoir-age correction as a function of $N$}

The inferred reservoir-age correction also depends upon the number of constituents and decreases by $75 \mathrm{yr}$ as $N$ goes from 2 to 11113 (Fig. 6). A decrease in the reservoir-age correction leads to a compensating increase in the radiocarbon age, as is evident in the standard radiocarbon-age equation. Understanding the radiocarbon age is important because it is almost identical to the lower bound, with a difference of no more than $7 \mathrm{yr}$ (recall Fig. 3). Changes in the reservoir-age correction are traced back to differences in the fraction of water originating from each surface source $m_{i}$ and the surface radiocarbon concentration associated with that source $C_{i}$.

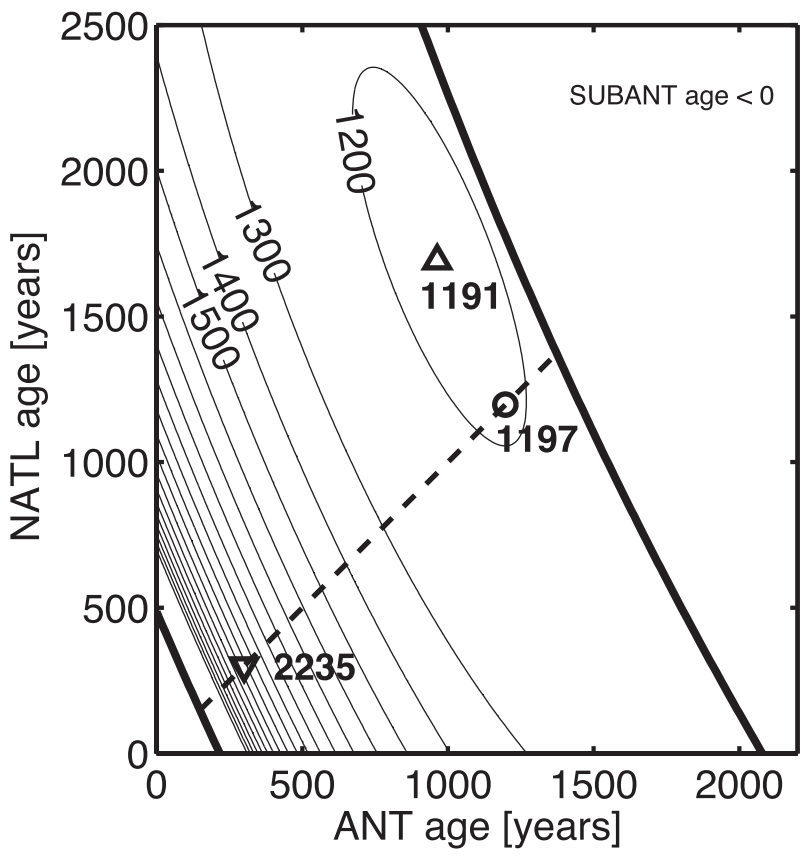

FIG. 5. As in Fig. 4, but now with three constituents coming from NATL, ANT, and SUBANT. To project the solution onto two dimensions, the SUBANT contribution is selected so as to satisfy the radiocarbon observation, given the NATL and ANT ages. Bold lines delineate the range of solutions, outside of which the SUBANT age would have to be negative (top right) or greater than $20000 \mathrm{yr}$ (toward the origin). The lower limit of mean age is unchanged from the two constituent solution (triangle), but the upper limit is almost $1000 \mathrm{yr}$ older at $2235 \mathrm{yr}$ (inverted triangle), where the same constraint that all constituents must be older than $300 \mathrm{yr}$ is applied. The dashed line $T_{\mathrm{ANT}}=T_{\mathrm{NATL}}$ is plotted for reference.

The inferred composition of the deep northeast $\mathrm{Pa}$ cific strongly depends upon $N$, as seen in Table 1 . No solution exists with $N=2$ that simultaneously fits all conservation equations, as could have been anticipated from the hydrographic census of Worthington (1981), but, if we restrict the data to phosphate and oxygen (e.g., Broecker et al. 1985, 1998), an apparent solution exists, yielding a NEPAC box filled with $69 \%$ Antarctic waters. For $N=3$, a solution exists when the analysis is limited to only phosphate, oxygen, and salinity data, yielding $62 \%$ Antarctic waters, though other solutions could be obtained from other combinations of data types. Using seven regions gives 53\% Antarctic water. For $N=2806$ and $N=11$ 113, the composition appears to converge with the smallest fraction of Antarctic water $(48 \%)$ and $21 \%$ North Atlantic water.

The effective source values for radiocarbon calculated by TMI differ from point values used in previous studies (Fig. 2). The center of the surface of the Weddell Sea has a radiocarbon concentration of $-140 \%$, as used previously to represent Antarctic Bottom Water (Broecker et al. 1998), but the periphery of the Weddell 


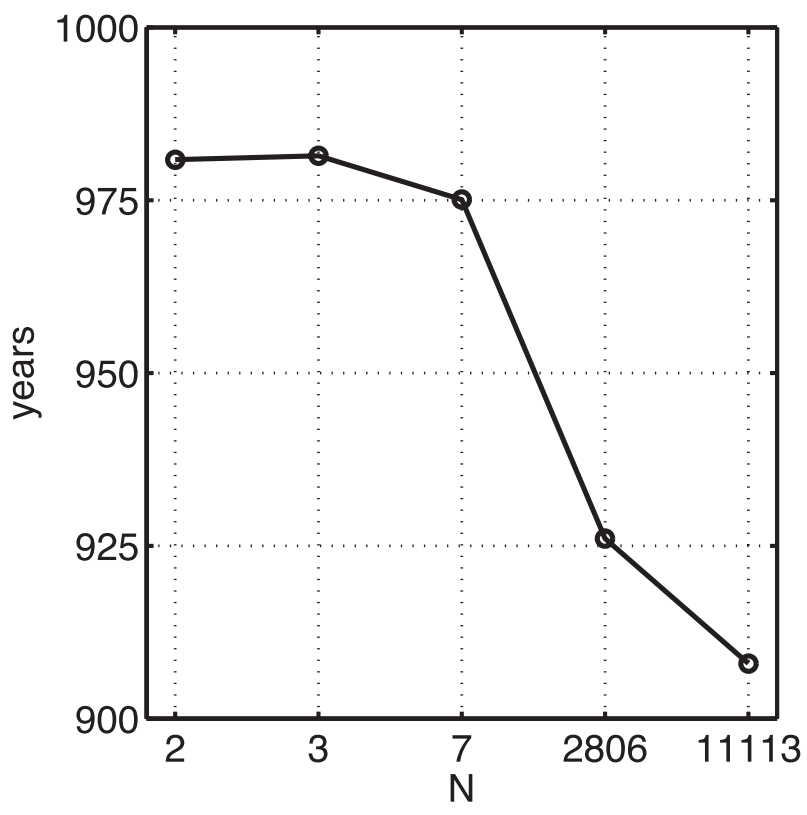

FIG. 6. Inferred reservoir-age correction for the NEPAC box as a function of the number of constituents $N$.

Sea has higher concentrations and these waters contribute to the Antarctic water in lesser but still significant amounts. The effective end member for Antarctic water is therefore somewhat altered to a value of $-137 \%$. The discrepancy is larger for the North Atlantic, where twice as much North Atlantic water is derived from the Nordic Seas as the Labrador Sea (Gebbie and Huybers 2010) and the often-used value of $-67 \%$ only represents the latter. We find that the effective initial radiocarbon concentration of the North Atlantic is $-57 \%$, although radiocarbon data are sparse in the Nordic Seas, making this estimate relatively uncertain.

The changes in the reservoir-age correction as a function of $N$ are explained by putting ocean waters into three categories: waters with reservoir ages that are large (ANT), medium [SUBANT and North Pacific (NPAC)], and small [NATL, ARC, the Mediterranean (MED), and the subtropics and tropics (TROP)]. The major change between $N=2$ and $N=11113$ cases is that about $20 \%$ of the large category is more correctly categorized as having medium reservoir ages. Because the difference in the reservoir-age correction between these two classes is approximately $400 \mathrm{yr}$, this reclassification changes the overall reservoir-age correction by about $80 \mathrm{yr}(0.2 \times 400 \mathrm{yr})$. If $-67 \%$ is used as the North Atlantic end member instead of $-57 \%$, the effective reservoir age for that end member is about $100 \mathrm{yr}$ older, which would offset about $20 \mathrm{yr}$ of the difference but not change the overall trend with $N$. Thus, the more detailed identification of the mixture of
TABLE 1. Decomposition of the deep NEPAC box according to number of constituents $N$ and the percentage of water from each surface region. Dashes denote values that are not applicable.

\begin{tabular}{rccccccc}
\hline \hline \multicolumn{1}{c}{$N$} & ANT & NATL & SUBANT & NPAC & ARC & MED & TROP \\
\hline 2 & 69 & 31 & - & - & - & - & - \\
3 & 62 & 26 & 12 & - & - & - & - \\
7 & 53 & 18 & 27 & 0 & 0 & 2 & 0 \\
2806 & 49 & 20 & 19 & 2 & 5 & 1 & 4 \\
11113 & 48 & 21 & 19 & 2 & 6 & 1 & 4 \\
\hline
\end{tabular}

waters is ultimately responsible for the changes in the lower bound as a function of $N$.

\section{c. Comparison with a previous observational estimate}

In the NEPAC box, we estimate $1264 \mathrm{yr}$ for the $N=$ 11113 lower bound; however, Matsumoto (2007) used the same GLODAP data and an $N=2$ solution and obtained a best estimate that is $200 \mathrm{yr}$ younger, raising the question of how their value could be below our lower bound. In fact, their estimate is lower than all of our lower bounds computed with any $N$. Two factors appear to account for the difference. First, the reservoir-age correction applied by Matsumoto (2007) is several decades larger, as is consistent with using a $N=2$ decomposition as shown in the previous subsection. The more important discrepancy, however, is that Matsumoto (2007) applied the reservoir-age correction in terms of the radiocarbon content, rather than an age correction, which leads to an error toward younger ages of about $150 \mathrm{yr}$. Indeed, if we subtract our initial radiocarbon value from our estimate of the NEPAC radiocarbon value (following paragraph 15 in Matsumoto 2007) and determine an age using the radiocarbon decay equation, we get a value of $1055 \mathrm{yr}$ (square in Fig. 3), similar to that of Matsumoto (2007) up to differences in the initial radiocarbon value applied. Such a method, however, is equivalent to performing the decay from too high an initial radiocarbon content and is incorrect.

\section{Using mixing histories to estimate mean age}

So far we have focused on the range of possible ages, which rules out some previous observational estimates as being too young, but no definitive statements could be made about the older model-based estimates. To obtain bounds, we used TMI to decompose interior ocean waters directly in terms of surface values, but TMI also permits the tracking of continuous pathways and the detailed mixing histories of interior waters. Thus, we proceed to make an estimate of the mean age consistent with the radiocarbon data and the pathways information contained in the World Ocean Circulation Experiment (WOCE) hydrographic climatology as extracted by TMI. 
Just as with the TMI solution for pathways (Gebbie and Huybers 2010), there is a local and global part to the solution. At the local level, we determine a residence time for each grid box and then use these residence times in a global inversion along with the pathway information to determine the distribution of aging.

\section{a. Local residence time}

In steady state, the radiocarbon concentration in an interior box is a sum of contributions from six neighboring boxes, less some amount of radioactive decay,

$$
C=\sum_{i=1}^{6} m_{i} C_{i}-C_{\text {sink }}
$$

where $m_{i}$ is now defined as the mass fraction of water contributed by each neighboring box as determined by TMI, $C_{i}$ is the observed radiocarbon concentration of each neighbor, and $C_{\text {sink }}$ is the sink of radiocarbon due to radioactive decay. In terms of the steady-state advectivediffusive balance, the input from neighboring boxes must balance the export and radioactive decay,

$$
\frac{d C}{d t}=\sum_{i=1}^{6} F_{i} C_{i}-F_{o} C-\lambda C=0,
$$

where $F_{i}$ is the volume flux from neighboring box $i$ and $F_{o}$ is the total volume flux out of all faces. All fluxes are divided by the volume of the interior box and have units of $\mathrm{s}^{-1}$. Multiplying the flux equation by the local residence time, $\tau=1 / F_{o}$, and enforcing a steady state leads to an equation similar to (7), but with different coefficients for the $C_{i}$ terms,

$$
C=\sum_{i=1}^{6} \frac{F_{i}}{F_{o}} C_{i}-\frac{\lambda C}{F_{o}}
$$

Comparing like terms, we find that $m_{i}=F_{i} / F_{o}$ and $C_{\text {sink }}=$ $\tau \lambda C$. In our case, the values of $\mathrm{C}$ are known from GLODAP and $C_{\text {sink }}$ can be computed for every interior box using the mass-weighted radiocarbon contributions from the neighboring boxes, yielding a value for the residence time of every interior box, $\tau=C_{\text {sink }} / \lambda C$. Note that a direct application to the GLODAP dataset yields some residence times that are unphysically negative, and thus our solution method must add an additional constraint (to be discussed in section 5c).

\section{b. Age as a global tracer}

Residence times of individual grid boxes are combined with the pathway information to determine the age in a manner similar to how TMI has been used to calculate the interior distribution of tracers (Gebbie and Huybers 2011). In this case, mean age is treated as a tracer $a$, sometimes identified as the ideal age tracer (cf. England 1995; Peacock and Maltrud 2006). Mean age is specified to be zero at the surface boundary and is subject to aging at a rate of one unit per unit of time in the interior,

$$
\frac{d a}{d t}=\sum_{i=1}^{6} F_{i} a_{i}-F_{o} a+1=0 .
$$

Multiplying by $\tau$ and using the findings from Eq. (9) permits the age tracer in each box to be represented as a sum of contributions from neighbors, plus a source $\tau$ equal to the local residence time,

$$
a=\sum_{i=1}^{6} m_{i} a_{i}+\tau .
$$

To calculate mean age globally, a matrix equation is formed with each row being the local mean age Eq. (11) at a particular location. To solve, we invert the matrix, $\mathbf{a}=\mathbf{A}^{-1} \mathbf{d}_{a}$, where $\mathbf{a}$ is a vector of the age tracer, $\mathbf{A}$ is the TMI pathways matrix, and $\mathbf{d}_{a}$ contains the zero-age boundary condition and internal sources in the form of local residence times. This methodology permits observational inference of mean age in a global framework.

\section{c. Application to radiocarbon observations}

Given that the GLODAP radiocarbon observations have relatively large uncertainties, we search for the smallest variations in the radiocarbon field that bring it into consistency with the steady-state circulation of TMI for both $N=2806$ and $N=11113$ [using the quadratic programming method from appendix $\mathrm{C}$ of Gebbie and Huybers (2010) that requires all residence times to be nonnegative]. We find that adjustments to the gridded radiocarbon field with a standard deviation of $6 \%$ are needed in both cases, consistent with the published error estimates of $5 \%-10 \%$ near the WOCE transects. We proceed with this solution but note that additional pieces of rate information, such as associated with geostrophy, nutrient remineralization, carbon cycle changes, or other transient tracers (e.g., Haine et al. 1995; Khatiwala et al. 2009; Holzer and Primeau 2010), could profitably be incorporated in the future.

The $N=11113$ case is presented in greater detail because it represents our best estimate of mean age. Because it is globally self-consistent with the TMI pathways, this estimate is spatially smooth, like GCM estimates (e.g., Peacock and Maltrud 2006), but is constrained at all 



FIG. 7. Age estimates at $2500-\mathrm{m}$ depth for $N=11113\left(2^{\circ} \times 2^{\circ}\right.$ resolution): (top left) best estimate and (top right) standard radiocarbon age. These panels are on the same color scale with a contour interval of $100 \mathrm{yr}$. The difference between (top left) and (top right) is due to TMI adjustments to (bottom left) radiocarbon concentration and (bottom right) the radiocarbon-age bias. The bottom panels have their own colorscales.

locations by observations (Fig. 7, top left). Note that internal local age minima are not allowed, but local maxima appear because of internal sources of the age tracer: for example, the 1500-yr maximum in the North Pacific and the deep North Indian maximum of $1400 \mathrm{yr}$. Some other notable features of the solution are mean ages greater than $1000 \mathrm{yr}$ everywhere north of the equator in the Pacific and Indian Oceans. Relatively young waters emanate from the North Atlantic and are preferentially transported along the western boundary, and a similarly young plume leaves the Weddell Sea and is entrained into the Antarctic Circumpolar Current.

These results can be compared against standard radiocarbon ages, where the reservoir-age correction is calculated with the unadjusted GLODAP data and the mixing fractions of $N=11113$ constituents but all other information is ignored (Fig. 7, top right). Our best age estimate has a similar spatial pattern to the standard radiocarbon age but is generally $50-200 \mathrm{yr}$ older. For example, the standard radiocarbon age in the NEPAC box is $1269 \mathrm{yr}$, whereas our best estimate is $1427 \mathrm{yr}$ (stars in Fig. 3). The lower bound, given a known watermass composition, is solved by an independent inverse problem at every gridpoint. As was found in the analysis of the NEPAC box, the difference between the standard radiocarbon age and the lower bound is very small, with a maximum difference of $8 \mathrm{yr}$, demonstrating that the standard radiocarbon age is nearly but not exactly equal to the lower bound.

The difference between the standard radiocarbon age and the best estimate is due to two effects. First, adjustments in the radiocarbon distribution are necessary to find consistency with the steady-state circulation. Although these changes are not typically larger than $10 \%$ at any location, a reasonable magnitude given the gaps between the WOCE transects and the difficulties of measuring in polar regions, this has an effect of up to $200 \mathrm{yr}$ on inferred radiocarbon age (Fig. 7, bottom left). In the boundary of the Weddell Sea, for example, the surface radiocarbon is adjusted to have $10 \%$ more radiocarbon, leading to the inference that waters at the bottom of the Weddell Sea are more than $100 \mathrm{yr}$ older on average. Second, a whole distribution of ages has been accounted for in our best estimate, unlike the standard radiocarbon-age calculation. The influence of these effects is diagnosed by taking the difference between our best age estimate and the standard radiocarbon age, after recalculating the latter using the TMI-adjusted radiocarbon values (Fig. 7, bottom right). The difference is the radiocarbon-age bias and is everywhere 



FIG. 8. Latitude-depth sections of mean age: (top) the Atlantic averaged between $60^{\circ} \mathrm{W}$ and $10^{\circ} \mathrm{E}$, (middle) the Indian Ocean between $40^{\circ}$ and $80^{\circ} \mathrm{E}$, and (bottom) the Pacific between the date line and $110^{\circ} \mathrm{W}$. The contour interval is 100 years in all panels.

less than $50 \mathrm{yr}$, a smaller factor than the TMI adjustments to the radiocarbon observations. Adding together the two effects quantified in the bottom panels of Fig. 7 explains the difference between the top panels of the figure.

These results can be compared against other observational and model studies of the mean age. Although the overall pattern is similar, the GCM estimate of Peacock and Maltrud (2006) found the North Pacific age maximum to be closer to $1700 \mathrm{yr}$ at a depth of $2000 \mathrm{~m}$, about $200 \mathrm{yr}$ older and $1000 \mathrm{~m}$ shallower than this work (Fig. 8). The inverse solution of Holzer and Primeau (2010) with ${ }^{39} \mathrm{Ar}$ observations found that the North Pacific is $1300_{-50}^{+200} \mathrm{yr}$ old and the pattern appears to be more in line with the TMI estimate. In the North Atlantic, the TMI estimate shows similarities to the western Atlantic observational estimate of Holzer et al. (2010). In both estimates, age increases with depth and toward the south, with 300-400-yr-old water at the seafloor at $30^{\circ} \mathrm{N}$. TMI indicates a South Atlantic maximum age of almost $800 \mathrm{yr}$ at $40^{\circ} \mathrm{S}$, and, although Holzer and Primeau (2010) do not produce an estimate at this latitude and depth, they show other bottom waters in the Atlantic as old as $600 \mathrm{yr}$.

\section{d. Transit time distributions}

The constraint of the mixing histories in the foregoing sections can also be cast in terms of estimating $G_{i}(t)$ in Eq. (1). To explicitly calculate these functions, the nonsteady version of Eq. (8) is used to infer the transient behavior of the mean age tracer following the same methodology as used in general circulation models (e.g.,

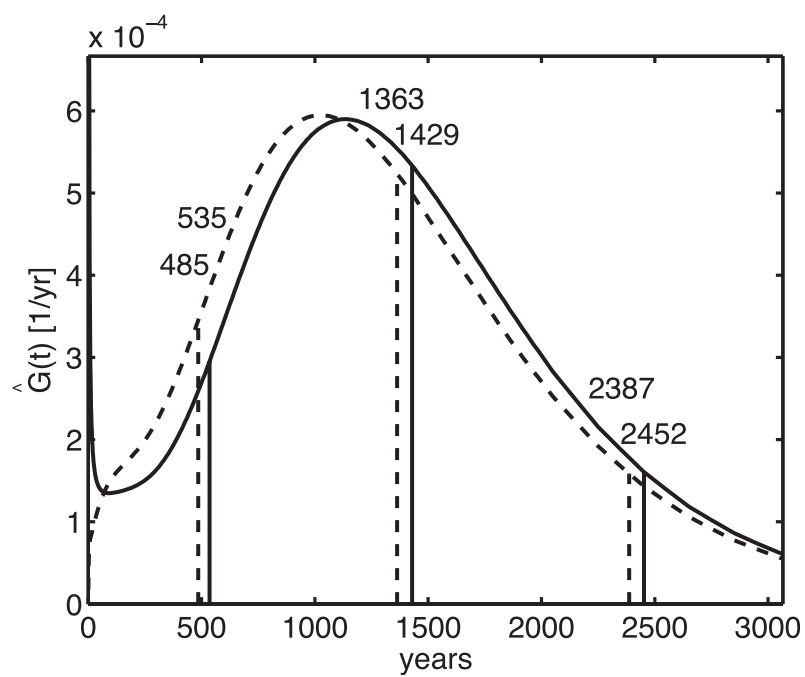

FIG. 9. TTDs for the deep NPAC (volume averaged over the NEPAC box) for the $2^{\circ}$ horizontal resolution solution (solid lines) and $4^{\circ}$ horizontal resolution solution (dashed lines). The vertical lines represent, from left to right, the $10 \%$ signal arrival time (485 and $535 \mathrm{yr}$ for $4^{\circ}$ and $2^{\circ}$, respectively), the mean age (1363 and $1429 \mathrm{yr}$, respectively), and the $90 \%$ equilibrium time (2387 and $2452 \mathrm{yr}$, respectively; cf. Wunsch and Heimbach 2008). The behavior at short lags (small $t$ ) is dominated by the uppermost waters in the NEPAC box (2000-m depth), where the $2^{\circ}$ case has fast vertical transmission of waters by numerical diffusion but in quantities small enough that the mean age is not significantly affected.

Khatiwala et al. 2001; Peacock and Maltrud 2006; Maltrud et al. 2010). Although all $11113 G_{i}(t)$ functions can be recovered at each location, here we focus on interpreting the global TTD from the sea surface to the NEPAC box, defined as $\hat{G}(t)=\sum_{i=1}^{N} m_{i} G_{i}(t)$. In this case, the TMI-constrained circulation is formulated as a forward advective-diffusive model, the entire sea surface is dyed, and the TTD is diagnosed from the movement of the dye tracer over a 10000 -yr integration. The centered first moment of the TTD is at $1429 \mathrm{yr}$ for $2^{\circ}$ horizontal resolution and at $1363 \mathrm{yr}$ for $4^{\circ}$ horizontal resolution (Fig. 9), nearly the same as the previously identified best estimates of mean age calculated by the equilibrium method of section $5 \mathrm{c}$. The width of the distribution, calculated as $\Delta=\sqrt{\left[1 / 2 \int_{0}^{\infty}(t-\bar{T})^{2} \hat{G}(t) d t\right]}$ (Hall and Plumb 1994), is 558 and $553 \mathrm{yr}$ for $2^{\circ}$ and $4^{\circ}$, respectively. As a check on this width, we note that the $2^{\circ}$ TMI-estimated TTD would lead to an inferred radiocarbon age of $1375 \mathrm{yr}$ and a radiocarbon-age bias of $54 \mathrm{yr}$, consistent with our earlier estimate, although there are minor differences because of details of the reservoir-age corrections and mixing histories.

These results can be compared against GCM and other observationally constrained estimates of TTDs. A GCM study (Peacock and Maltrud 2006) found that TTDs in 
the North Pacific at 2000-m depth were somewhat wider at $650-700 \mathrm{yr}$. The TTD mean-to-width ratio $(\bar{T} / \Delta)$ is about 2.5 for TMI at both resolutions, whereas the GCM estimate appears to be smaller at 2.0-2.3, indicating that the GCM is more diffusive than the TMI circulation (relative to advective processes; see Mouchet and Deleersnijder 2008). Both the GCM and TMI TTDs have a mean-to-width ratio generally consistent with a North Pacific observational estimate (Holzer and Primeau 2010) that found a range of possible ratios from 1 to 6 . We note that Khatiwala et al. (2009) also empirically constrained TTDs but using a maximum entropy methodology to regularize an otherwise underdetermined formulation of the problem, and in future work it would be useful to compare the relative merits and constraints provided by TMI and other methodologies (e.g., DeVries and Primeau 2011).

\section{e. Uncertainties in the age estimate}

There are several perspectives that we can offer on the uncertainty in the mean age estimates presented here. First, we note that the effect of including the mixing history, as encapsulated in the form of the $G_{i}(t)$ functions, is to alter the standard radiocarbon age by no more than 50 yr (e.g., Fig. 7). Thus, although the $G_{i}(t)$ functions may be uncertain, we expect their shape to introduce errors in the mean age of no more than $50 \mathrm{yr}$. We also note, however, that the age estimates presented here, along with previous observational and modeling studies, do not account for the influence of exotic waters such as from groundwater seepage, hydrothermal vents, or ice sheets. These exotic waters could have extremely old ages, and, although their exclusion has the practical utility of making our estimates easier to compare with GCM results, it would nonetheless be of interest to investigate their influence in future work.

To explore the uncertainty due to the water-mass decomposition, we compare the $2^{\circ}$ and $4^{\circ}$ reservoir-age corrections as computed with the gridded GLODAP data (Fig. 10, top). The differences are generally less than $50 \mathrm{yr}$, especially in the regions of the oldest ocean waters. The reservoir-age correction at middepth in the Ross Sea, however, is $100 \mathrm{yr}$ smaller in the $2^{\circ}$ estimate. As mentioned in previous work (Gebbie and Huybers 2011), the major difference between the two estimates is the ratio of Weddell to Ross Sea contributions in AABW. In the $2^{\circ}$ estimate, a smaller amount of deep water originates from the Ross Sea, giving a smaller influx of young waters to depth and accounting for the smaller reservoir-age correction. Although these local errors can reach $100 \mathrm{yr}$, the uncertainties in the watermass decomposition have a smaller influence on basin scale age estimates, such as for the deep North Pacific, where the difference between the $2^{\circ}$ and $4^{\circ}$ reservoirage corrections is only $19 \mathrm{yr}$ in the NEPAC box.

The largest uncertainties that we identify have to do with surface source radiocarbon values. For example, when the reservoir-age correction is recalculated with the $2^{\circ}$ TMI-adjusted radiocarbon distribution, the deep Pacific reservoir-age correction is $100 \mathrm{yr}$ smaller than when the raw GLODAP gridded data are used (Fig. 10, bottom). Overall, uncertainties in the surface radiocarbon values lead to age uncertainties roughly twice as large as those due to the water-mass decomposition. The differences in source radiocarbon are consistent with the reported measurement errors, though also arise from errors in the TMI estimates, possibly because of violations of the steady-state assumption. Errors in removing the influence of bomb radiocarbon could also be important (e.g., Rubin and Key 2002).

\section{Conclusions}

Previous observational estimates of ocean age from radiocarbon included a number of hidden uncertainties, especially because of the use of a small number of constituents to describe water sources. In this study, we use a comprehensive pathways and mixing model with an inverse method to estimate the age of the ocean and its upper and lower bounds, while investigating the sensitivity to the number of constituents from 2 to 11113 . There are three major considerations in the determination of ocean age: the ambiguous decomposition of waters into the constituents necessary for calculation of the reservoir-age correction, the influence of multiple transit times in interpretation of the radiocarbon constraint, and observational errors in radiocarbon. To address the first issue, we use the TMI-derived ocean decomposition that is trained with a full suite of tracers, including $\delta^{18} \mathrm{O}$, nutrients, temperature, and salinity. Extending the analysis to include radiocarbon, we find that the range of possible ages strongly depends on the number of constituents, because radiocarbon observations have difficulty ruling out the presence of small amounts of very old water. In addressing the second issue, we quantify the bias in radiocarbon age without reliance on numerical models or imposed mixing parameters by using the mixing history implicit in TMI. Observational estimates that do not differentiate between the transit times of different water masses are biased very near to the lower limit of all possible ages. The third issue involves the uncertainties associated with measurement errors, data sparsity, and the difficulty in distinguishing bomb and natural radiocarbon, which is partially addressed by adjusting the radiocarbon dataset into consistency with a steady-state circulation 

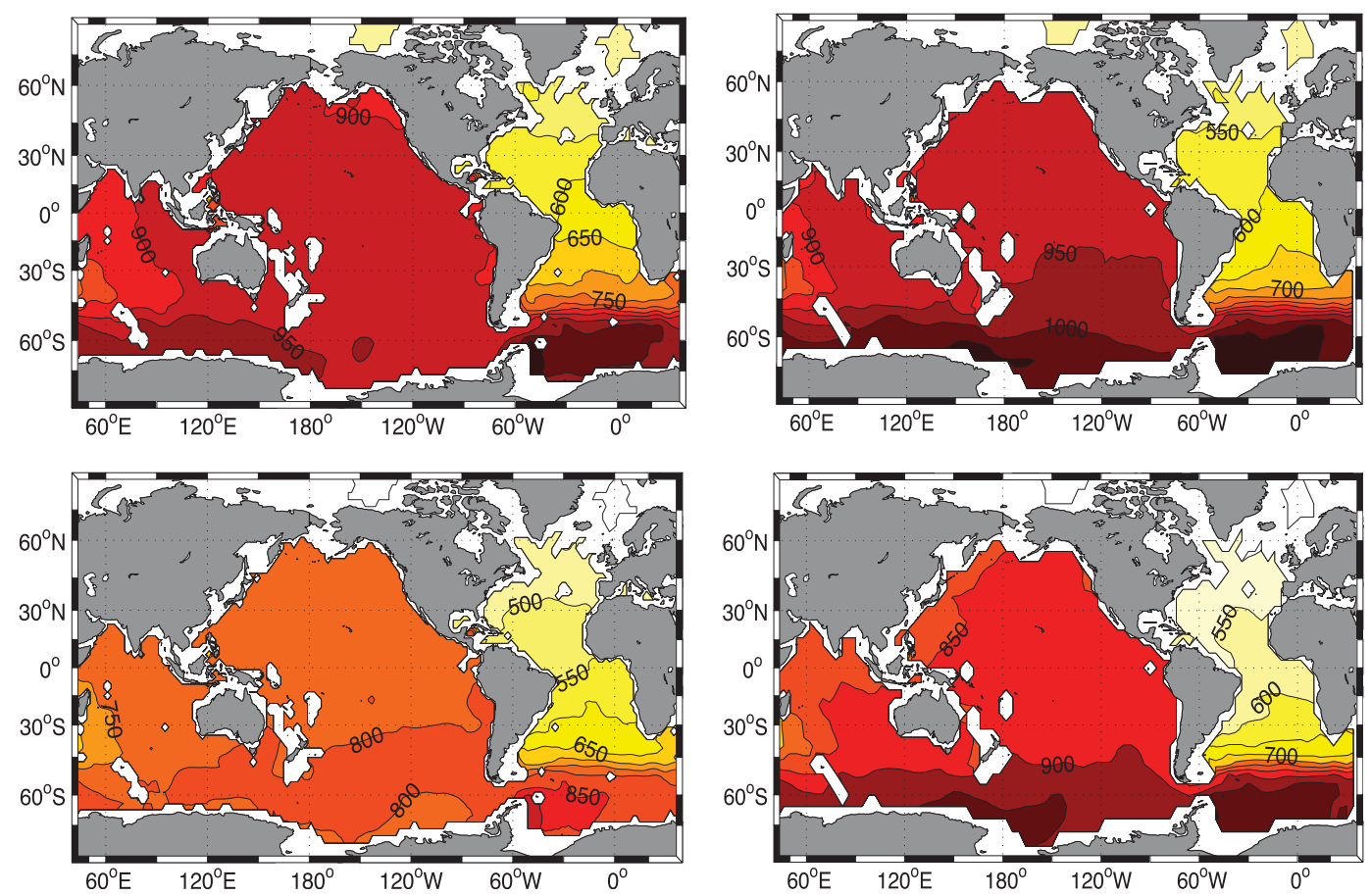

FIG. 10. Reservoir-age correction at 2500-m depth for four different solutions: the GLODAP data at (top left) $2^{\circ}$ and (top right) $4^{\circ}$ resolutions and for the TMI-adjusted steady-state radiocarbon fields at (bottom left) $2^{\circ}$ and (bottom right) $4^{\circ}$ resolutions. The contour interval is $50 \mathrm{yr}$.

field. Taking these factors into account, we find that radiocarbon data constrain the deep North Pacific to be more than $1100 \mathrm{yr}$ old, with the full mixing history suggesting ages of 1200-1500 yr over the region.

The lower limit of the mean age of the North Pacific is higher than the best estimates of some previous observational studies (Stuiver et al. 1983; Matsumoto 2007). Using up to 11113 surface sources, the reservoirage correction is diagnosed to be $100 \mathrm{yr}$ younger than previously thought. It is the broadness of surface regions contributing to the deep (Gebbie and Huybers 2011) that influences the needed reservoir correction and age estimates. Model estimates, on the other hand, are 100$400 \mathrm{yr}$ older than our current best estimate of the mean age of the deep North Pacific (Primeau 2005; Peacock and Maltrud 2006). We suspect that some models have older ages because of increased mixing associated with their coarse resolution, consistent with the finding that the transit time distributions of a GCM have a smaller mean-to-width ratio than the TMI estimate, although this can likely explain no more than $50 \mathrm{yr}$ of the additional aging through the enhancement of the radiocarbon-age bias. It will be of great interest to see estimates of age from numerical models with higher resolution (e.g., Maltrud et al. 2010), as well as further analysis including additional observational constraints.
Acknowledgments. Helpful comments were provided by Luke Skinner and Carl Wunsch. GG is supported by the J. Lamar Worzel Assistant Scientist Fund and the Penzance Endowed Fund in Support of Assistant Scientists. PJH is supported by NSF Award 0960787.

\section{APPENDIX}

\section{Lower Bound on Mean Age}

\section{a. Lagrange multiplier method for advective-diffusive transport}

Finding the minimum value of the mean age subject to a radiocarbon observation is equivalent to finding the stationary point of a Lagrangian function $\mathcal{L}$, where generalized Lagrange multipliers $\mu, \pi$, and $\rho$ are appended for equality and inequality constraints (Fiacco and McCormick 1968). The Lagrangian is

$$
\begin{aligned}
\mathcal{L}= & \sum_{i=1}^{N} m_{i} \int_{t=0}^{\infty} t G_{i}(t) d t-\mu\left[C-\sum_{i=1}^{N} m_{i} C_{i} \int_{0}^{\infty} G_{i}(t) e^{-\lambda t} d t\right] \\
& +\sum_{i=1}^{N} \pi_{i}(t) G_{i}(t)+\sum_{i=1}^{N} \rho_{i}\left[\int_{t=0}^{\infty} G_{i}(t) d t-1\right], \quad(\mathrm{A} 1)
\end{aligned}
$$


where the first term is the mean age, the $\mu$ term enforces the data constraint, the $\pi_{i}(t)$ terms enforce $G_{i}(t) \geq 0$, and the $\rho_{i}$ terms enforce $\int_{0}^{\infty} G_{i}(t) d t=1$. The solution, $G_{i}(t)=$ $\delta\left(t-T_{i}\right), T_{i}=(1 / \lambda) \log \left(C_{i} / C\right), \mu=1 /(\lambda C), \pi_{i}(t)=m_{i} t+$ $m_{i} \mu \exp (-\lambda t)+\rho_{i}$, and $\rho_{i}=-m_{i}\left[(1 / \lambda)+T_{i}\right]$, satisfies the Karush-Kuhn-Tucker conditions (Fiacco and McCormick 1968; Strang 1988) and therefore is a stationary point. By substitution, this stationary point is a minimum. The case where one or more $C_{i}<C$ is discussed below.

\section{b. Lagrange multiplier method for advective transport}

Here, we illustrate a simpler way to understand the lower bound solution. As found above, all minimum-age solutions are obtained when the $G_{i}(t)$ functions are delta functions, and thus the expression for the mean age and the radiocarbon constraint can be simplified. Now, the Lagrangian function is

$$
\mathcal{L}=\sum_{i=1}^{N} m_{i} T_{i}-\mu\left(C-\sum_{i=1}^{N} m_{i} C_{i} e^{-\lambda T_{i}}\right)
$$

The stationary point satisfies $\partial \mathcal{L} / \partial \mu=0$ and $\partial \mathcal{L} / \partial T_{i}=0$ for $i=1 \rightarrow N$; thus,

$$
\frac{\partial \mathcal{L}}{\partial T_{i}}=m_{i}-\mu\left(m_{i} C_{i} \lambda e^{-\lambda T_{i}}\right)=0
$$

which is solved for all of the transit times, $T_{i}=(1 / \lambda)$ $\log \left(\mu \lambda C_{i}\right)$. Note that there is one equation for each $T_{i}$, for a total of $N$ equations. The only unknown term is the scalar Lagrange multiplier $\mu$. One way to solve for $\mu$ is to multiply both sides of (A3) by $m_{i}$, then sum the $N$ equations, and substitute in the radiocarbon constraint, leading to $\mu=1 /(\lambda C)$. Now we can back substitute to solve for $T_{i}$. All $T_{i}$ have the same form: namely,

$$
T_{i}=\frac{1}{\lambda} \log \left(\frac{C_{i}}{C}\right)
$$

By substitution into the definition of the mean age, the stationary point is a minimum,

$$
\bar{T}_{\min }=\sum_{i=1}^{N} \frac{m_{i}}{\lambda} \log \left(\frac{C_{i}}{C}\right) .
$$

This stationary point only holds if it is in the feasible range: that is, $T_{i} \geq 0$, which implies a bound on the radiocarbon concentrations, $C_{i} \geq C$. The next section shows how the problem can be solved in the case that the radiocarbon bounds do not hold.

\section{c. Recursive method to handle nonnegative constraints}

If the method outlined above produces a solution with negative age components, those $T_{i}$ values are set to zero by the Karush-Kuhn-Tucker conditions (e.g., Wunsch 1996). Resolving for the partial derivatives of the objective function with the added constraints, we find that

$$
T_{i}=\frac{1}{\lambda} \log \left(\frac{\sum_{j=Q+1}^{N} m_{j} C_{i}}{C-\sum_{k=1}^{Q} m_{k} C_{k}}\right), \text { for } i=Q+1 \rightarrow N,
$$

and $T_{i}=0$ for $i=1 \rightarrow Q$, with ordering such that $C_{i}<C$ for all $i \leq Q$. In the case that there are $T_{i}$ terms that are less than zero, this process is repeated iteratively until the solution is in the feasible range. By comparison with the results of nonlinear programming algorithms, we find the same result but with a substantial reduction of computational cost.

\section{REFERENCES}

Anderson, L., and J. Sarmiento, 1994: Redfield ratios of remineralization determined by nutrient data analysis. Global Biogeochem. Cycles, 8, 65-80.

Broecker, W. S., and T. H. Peng, 1982: Tracers in the Sea. LamontDoherty Earth Observatory of Columbia University, 690 pp.

_ - T. Takahashi, and T. Takahashi, 1985: Sources and flow patterns of deep-ocean waters as deduced from potential temperature, salinity, and initial phosphate concentration. J. Geophys. Res., 90 (C4), 6925-6939.

— S. Blanton, W. M. Smethie Jr., and G. Ostlund, 1991: Radiocarbon decay and oxygen utilization in the deep Atlantic Ocean. Global Biogeochem. Cycles, 5, 87-117.

- and Coauthors, 1998: How much deep water is formed in the Southern Ocean? J. Geophys. Res., 103 (C8), 15 833-15 843.

— E. Elark, S. Barker, I. Hajdas, G. Bonani, and E. Moreno, 2007: Radiocarbon age of late glacial deep water from the equatorial Pacific. Paleoceanography, 22, PA2206, doi:10.1029/ 2006PA001359.

Deleersnijder, E., J. M. Campin, and E. J. M. Delhez, 2001: The concept of age in marine modelling I. Theory and preliminary model results. J. Mar. Syst., 28 (3-4), 229-267.

DeVries, T., and F. Primeau, 2011: Dynamically and observationally constrained estimates of water-mass distributions and ages in the global ocean. J. Phys. Oceangr., 41, 2381-2401.

England, M. H., 1995: The age of water and ventilation timescales in a global ocean model. J. Phys. Oceanogr., 25, 2756-2777.

Fiacco, A., and G. McCormick, 1968: Nonlinear Programming. Wiley, $210 \mathrm{pp}$.

Fiadeiro, M., 1982: Three-dimensional modeling of tracers in the deep Pacific Ocean II. Radiocarbon and the circulation. J. Mar. Res., 40, 537-550. 
Gebbie, G., and P. Huybers, 2010: Total matrix intercomparison: A method for resolving the geometry of water-mass pathways. J. Phys. Oceanogr., 40,1710-1728.

_- and _- 2011: How is the ocean filled? Geophys. Res. Lett., 38, L06604, doi:10.1029/2011GL046769.

Gouretski, V., and K. Koltermann, 2004: WOCE global hydrographic climatology. Berichte des Bundesamtes für Seeschifffahrt und Hydrographie Tech. Rep. 35, 52 pp.

Haine, T. W. N., and T. M. Hall, 2002: A generalized transport theory: Water-mass composition and age. J. Phys. Oceanogr., 32, 1932-1946.

— A. J. Watson, and M. I. Liddicoat, 1995: Chlorofluorocarbon113 in the northeast Atlantic. J. Geophys. Res., 100 (C6), $10745-10753$.

Hall, T. M., and R. A. Plumb, 1994: Age as a diagnostic of stratospheric transport. J. Geophys. Res., 99 (D1), 1059-1070.

Holzer, M., and T. M. Hall, 2000: Transit-time and tracer-age distributions in geophysical flows. J. Atmos. Sci., 57, 3539-3558.

—, and F. W. Primeau, 2010: Improved constraints on transit time distributions from argon 39: A maximum entropy approach. J. Geophys. Res., 115, C12021, doi:10.1029/2010JC006410.

,-- W. M. Smethie Jr., and S. Khatiwala, 2010: Where and how long ago was water in the western North Atlantic ventilated? Maximum-entropy inversions of bottle data from WOCE line A20. J. Geophys. Res., 115, C07005, doi:10.1029/ 2009JC005750.

Jones, G., A. Gagnon, K. von Reden, A. McNichol, and R. Schneider, 1994: High-precision AMS radiocarbon measurements of central Arctic Ocean sea waters. Nucl. Instrum. Methods Phys. Res. B, 92 (1-4), 426-430.

Kadko, D., J. Baross, and J. Alt, 1995: The Magnitude and Global Implications of Hydrothermal Flux. Geophys. Monogr., Vol. 91 Amer. Geophys. Union, 446 pp.

Karstensen, J., and M. Tomczak, 1998: Age determination of mixed water masses using CFC and oxygen data. J. Geophys. Res., 103 (C9), 18 599-18 609.

Key, R. M., and Coauthors, 2004: A global ocean carbon climatology: Results from Global Data Analysis Project (GLODAP). Global Biogeochem. Cycles, 18, GB4031, doi:10.1029/2004GB002247.

Khatiwala, S., M. Visbeck, and P. Schlosser, 2001: Age tracers in an ocean GCM. Deep-Sea Res. I, 48, 1423-1441.

— , F. Primeau, and T. Hall, 2009: Reconstruction of the history of anthropogenic $\mathrm{CO}_{2}$ concentrations in the ocean. Nature, 462, 346-349.

Kroopnick, P., 1985: The distribution of ${ }^{13} \mathrm{C}$ of $\Sigma \mathrm{CO}_{2}$ in the world oceans. Deep-Sea Res., 32A, 57-84.

Lawson, C. L., and R. J. Hanson, 1974: Solving Least-Squares Problems. Prentice Hall, 337 pp.

Legrande, A. N., and G. A. Schmidt, 2006: Global gridded data set of the oxygen isotopic composition in seawater. Geophys. Res. Lett., 33, L12604, doi:10.1029/2006GL026011.

Mackas, D. L., K. L. Denman, and A. F. Bennett, 1987: Leastsquares multiple tracer analysis of water mass composition. J. Geophys. Res., 92 (C3), 2907-2918.
Maltrud, M., F. Bryan, and S. Peacock, 2010: Boundary impulse response functions in a century-long eddying global ocean simulation. Environ. Fluid Mech., 10, 275-295.

Matsumoto, K., 2007: Radiocarbon-based circulation age of the world oceans. J. Geophys. Res., 112, C09004, doi:10.1029/ 2007JC004095.

Metz, B., O. Davidson, H. de Coninck, M. Loos, and L. Meyer, Eds., 2005: Carbon Dioxide Capture and Storage. Cambridge University Press, $431 \mathrm{pp}$

Mouchet, A., and E. Deleersnijder, 2008: The leaky funnel model, a metaphor of the ventilation of the World Ocean as simulated in an OGCM. Tellus, 60A, 761-774.

Peacock, S., and M. Maltrud, 2006: Transit-time distributions in a global ocean model. J. Phys. Oceanogr., 36, 474-495.

Primeau, F., 2005: Characterizing transport between the surface mixed layer and the ocean interior with a forward and adjoint global ocean transport model. J. Phys. Oceanogr., 35, 545-564.

— Residence-time and ventilation-rate distributions of water masses. J. Phys. Oceanogr., 36, 1439-1456.

Rubin, S. I., and R. M. Key, 2002: Separating natural and bombproduced radiocarbon in the ocean: The potential alkalinity method. Global Biogeochem. Cycles, 16, 1105, doi:10.1029/ $2001 \mathrm{~GB} 001432$.

Schlosser, P., and Coauthors, 1997: The first trans-Arctic ${ }^{14} \mathrm{C}$ section: Comparison of the mean ages of the deep waters in the Eurasian and Canadian basins of the Arctic Ocean. Nucl. Instrum. Methods Phys. Res., 123B (1-4), 431-437.

Straneo, F., R. Curry, D. Sutherland, G. Hamilton, C. Cenedese, K. Våge, and L. Stearns, 2011: Impact of fjord dynamics and glacial runoff on the circulation near Helheim Glacier. Nat. Geosci., 4, 322-327.

Strang, G., 1988: Linear Algebra and Its Applications. 3rd ed. Harcourt Brace Jovanovich, 505 pp.

Stuiver, M., P. D. Quay, and H. G. Ostlund, 1983: Abyssal water $\mathrm{C}-14$ distribution and the age of the world oceans. Science, 219, 849-851.

Tomczak, M., and D. G. B. Large, 1989: Optimum multiparameter analysis of mixing in the thermocline of the eastern Indian Ocean. J. Geophys. Res., 94 (C11), 16 141-16 149.

Waugh, D. W., T. M. Hall, and T. W. N. Haine, 2003: Relationships among tracer ages. J. Geophys. Res., 108, 3138, doi:10.1029/ 2002JC001325.

Worthington, L., 1981: The water masses of the World Ocean: Some results of a fine-scale census. Evolution of Physical Oceanography: Scientific Surveys in Honor of Henry Stommel, B. A. Warren and C. Wunsch, Eds., MIT Press, 42-60.

Wunsch, C., 1996: The Ocean Circulation Inverse Problem. Cambridge University Press, $437 \mathrm{pp}$.

_ 2002: Oceanic age and transient tracers: Analytical and numerical solutions. J. Geophys. Res., 107, 3048, doi:10.1029/ 2001JC000797.

- and P. Heimbach, 2008: How long to oceanic tracer and proxy equilibrium? Quat. Sci. Rev., 27, 637-651. 